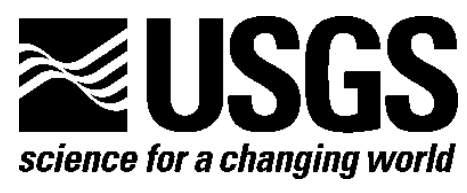

\title{
Feasibility Study for the Quantitative Assessment of Mineral Resources in Asteroids
}

By Laszlo Keszthelyi, Justin Hagerty, Amanda Bowers, Karl Ellefsen, Ian Ridley, Trude King, David Trilling, Nicholas Moskovitz, and Will Grundy

Open-File Report 2017-1041

U.S. Department of the Interior

U.S. Geological Survey 


\section{U.S. Department of the Interior \\ RYAN K. ZINKE, Secretary}

\section{U.S. Geological Survey \\ William H. Werkheiser, Acting Director}

U.S. Geological Survey, Reston, Virginia: 2017

For more information on the USGS—-the Federal source for science about the Earth, its natural and living resources, natural hazards, and the environment-visit https://www.usgs.gov/ or call 1-888-ASK-USGS (1-888-275-8747).

For an overview of USGS information products, including maps, imagery, and publications, visit https://store.usgs.gov.

Any use of trade, firm, or product names is for descriptive purposes only and does not imply endorsement by the U.S. Government.

Although this information product, for the most part, is in the public domain, it also may contain copyrighted materials as noted in the text. Permission to reproduce copyrighted items must be secured from the copyright owner.

\section{Suggested citation:}

Keszthelyi, L., Hagerty, J., Bowers, A., Ellefsen, K., Ridley, I., King, T., Trilling, D., Moskovitz, N., and Grundy, W., 2017, Feasibility study for the quantitative assessment of mineral resources in asteroids: U.S. Geological Survey Open-File Report 2017-1041, 28 p., https://doi.org/10.3133/ofr20171041. 


\section{Contents}

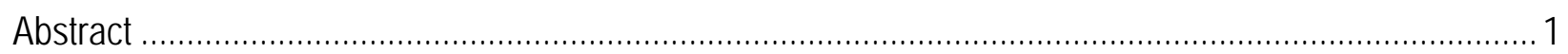

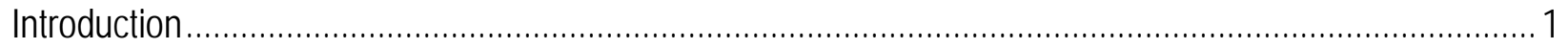

Why Asteroid Mineral Resources Matter .................................................................................... 1

How USGS Conducts Quantitative Resource Assessments ............................................................ 2

Descriptive Model for Asteroids ............................................................................................

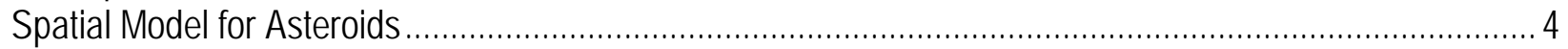

Deposit-Density Model for Near-Earth Objects ..........................................................................

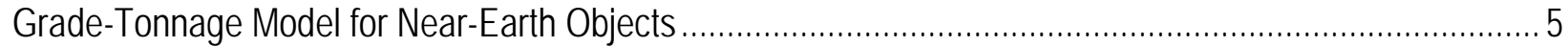

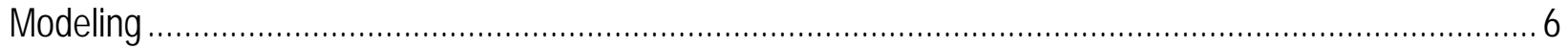

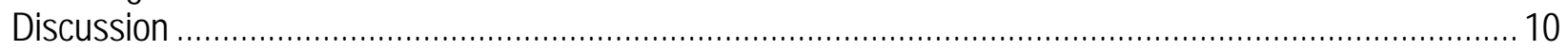

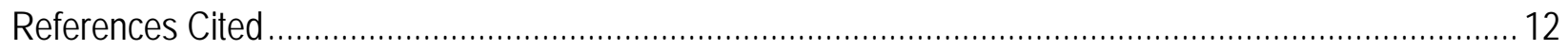

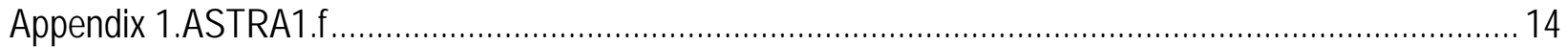

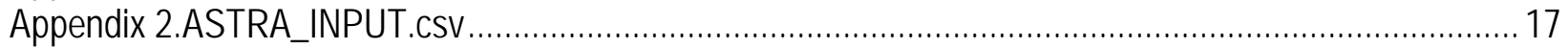

\section{Figures}

1. Flowchart for USGS resource assessments ......................................................................... 3

2. Cumulative volume of near-Earth objects (NEOs) versus NEO diameter calculated from observed

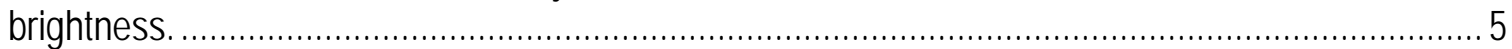

3. Cumulative distribution function of absolute magnitude of the 428 known objects included in this

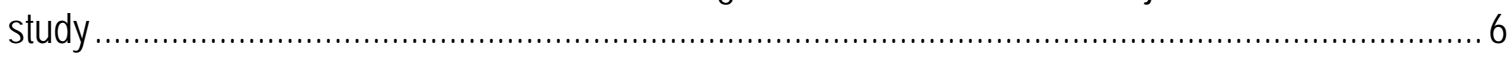

4. Curve fits to the meteorite composition compilation of Nittler and others (2004).......................... 9

5. Output of ASTRA1 modeling showing how the minimum amount of water and metallic iron resources in near-Earth objects would be represented in a USGS resource assessment.

\section{Tables}

1. Association among spectral types and meteorite groups in this study. 7

2. Density range for each composition group derived from data compiled by Carry (2012).....

3. Mapping among compositional groups for this study and meteorite classes from Nittler and others (2004).

4. Minimum amount of water and metallic iron resources in near-Earth objects.............................. 11 


\title{
Feasibility Study for the Quantitative Assessment of Mineral Resources in Asteroids
}

By Laszlo Keszthelyi ${ }^{1}$, Justin Hagerty ${ }^{1}$, Amanda Bowers ${ }^{1}$, Karl Ellefsen ${ }^{1}$, lan Ridley¹, Trude King ${ }^{1}$, David Trilling², Nicholas Moskovitz ${ }^{3}$, and Will Grundy 3

\begin{abstract}
This study was undertaken to determine if the U.S. Geological Survey’s process for conducting mineral resource assessments on Earth can be applied to asteroids. Successful completion of the assessment, using water and iron resources to test the workflow, has resulted in identification of the minimal adjustments required to conduct full resource assessments beyond Earth. We also identify the types of future studies that would greatly reduce uncertainties in an actual future assessment. Whereas this is a feasibility study and does not include a complete and robust analysis of uncertainty, it is clear that the water and metal resources in near-Earth asteroids are sufficient to support humanity should it become a fully space-faring species.
\end{abstract}

\section{Introduction}

\section{Why Asteroid Mineral Resources Matter}

The long-term goal of the United States space program is establishing a human presence on Mars. This goal has been remarkably stable for decades, unfazed by changes in administration, geopolitical situations, economic conditions, and trends in public opinion. One can debate the merit of this goal, but it is a remarkably consistent aspect of our Nation's space policy.

Several major challenges must be overcome before there are human bootprints on Mars. The most problematic obstacle may be the price tag - a large fraction of which is in hauling material out of Earth's gravity well. Obtaining key resources (for example, water and metals) in the space between Earth and Mars could dramatically reduce the costs of a trip to Mars. The obvious way to obtain such resources is to mine near-Earth objects (NEOs). Such mining may be essential to sustaining a human presence beyond Earth's orbit.

Before a prudent mission architecture can rely on resources obtained in space, an unbiased, quantitative, and reliable assessment of those resources is needed. Creating such an assessment is the Congressionally mandated responsibility of the U.S. Geological Survey (USGS). The “Organic Act” of 1879 established the USGS with a few specific obligations, including "the classification of public lands and examination of the geologic structure, mineral resources, and products...” In 1962, Congress extended those examinations to "beyond the borders of the United States.” In 2015, USGS management

\footnotetext{
${ }^{1}$ U.S. Geological Survey

${ }^{2}$ Northern Arizona University

${ }^{3}$ Lowell Observatory
} 
recognized that this applies to space, and especially to asteroids. At this time Congress has not provided funding specifically to assess asteroid resources. Nevertheless, the USGS Mineral Resources Program has decided it is prudent to fund a small feasibility study to examine if existing terrestrial methods can be applied to asteroids. This report details the steps taken as part of that study and its final results.

When it comes to asteroid mining, platinum and other rare metals have garnered the most public attention-with published reports suggesting that asteroids will provide trillions of dollars in return for the investment in asteroid mining infrastructure (Ostro and others, 1991; Gerlach, 2005). The methods we used in this study could be applied to platinum, but we have chosen to focus on two more practical resources: water and native metal (iron-nickel alloy). Water from asteroids has the potential to dramatically reduce the cost of long-term human presence beyond Earth's orbit as a source of drinking water, radiation shielding, oxygen to breathe, and rocket fuel (Gerlach, 2005; Lewis, 2014). Iron-nickel alloy from asteroids could be directly used in space structures; 3D printing of complex parts from such materials has been demonstrated and should be possible in space. However, we emphasize that the objective of this study was not to complete a proper assessment of any asteroid resource, but instead to test the feasibility of doing such resource assessments in the future.

\section{How USGS Conducts Quantitative Resource Assessments}

The methodology used by the USGS is geared to produce unbiased and reliable results in a format readily understood by decisionmakers who are not technical experts in the field (for example, Singer, 2007). The methodology is often called the "three-part" model because it uses three separate quantitative models that are combined using numerical methods to produce the statistics for the final assessment (fig. 1). For each resource, a prerequisite for quantitative assessments is the development of qualitative "descriptive models" of each geologic setting in which the resource can be found. This is a description of the association among the resource, the geologic processes that form deposits of that resource and the rock assemblages that contain those deposits. For mineral assessments on Earth, the descriptive models are recorded in a standardized form to ensure consistent information content. This form includes key scientific references, type localities, geologic context, and typical alteration and weathering.

The first of the three quantitative models is the "spatial model," which delineates tracts that contain the geologic setting described in the descriptive model. In other words, the spatial model is a map of the areas where the geology permits the existence of deposits of the resource (Singer, 2007). Thus, this model is not an attempt to map the resource deposits themselves. The spatial model can exclude areas inaccessible owing to technical, political, or legal reasons. A wide variety of relevant data, including information on known deposits, geochemistry of samples, geophysical surveys, geologic mapping, and remote sensing can be used in creating this model. The spatial variability in the quality of the data is also considered.

The second quantitative model is the "grade-tonnage model” for each geologic setting. "Grade" is the concentration (or quality) of the resource and "tonnage" is the mass (or quantity) of the deposit. These models are usually expressed mathematically as multivariate probability density functions for the resource concentrations and ore tonnages of the deposits in the assessment area. These functions are usually visualized in two plots: (1) a size-frequency distribution and (2) a quality-frequency distribution of the deposits. These models usually rely on previous in-depth investigations of localities analogous to the assessment area. The distributions are fit with a statistical model using a series of tests to ensure that the model correctly represents the typical highly skewed size distributions. This graphical analysis can also reveal if there are multiple populations of deposits. In such a circumstance, it is necessary to 
distinguish the geologic settings of the different populations and develop new descriptive and spatial models for each.

The third quantitative model is the "deposit-density model," which provides an estimate of the expected number of deposits per unit area. This estimate is usually determined by examining a statistically meaningful number of localities in sufficient detail that the number of deposits in these areas is known with some certainty. Such studies take advantage of a wide variety of geologic and geophysical datasets, creating deep understanding that can be described as "geologic intuition" of the problem. Mathematically, this understanding is expressed as a probability mass function for the number of deposits per unit area, which can be calculated in conjunction with the development of grade-tonnage models. Again, there are a number of statistical tests to identify when multiple populations are being mixed and to provide a robust description of the uncertainty in the deposit-density estimates.

The deposit-density and grade-tonnage models are first statistically combined to calculate the expected size and quality distribution of deposits per unit area at various confidence levels (typically 10, 50, and 90 percent). Monte Carlo methods are the most commonly used statistical method because of their flexibility and mathematical simplicity. Then, an economic model that describes the cost to set up an extraction operation and then operate it can be applied. Even a simple parametric model can be sufficient to indicate whether the expected deposits are worth extracting. After combining with the areas identified in the spatial model, the final outputs are (1) the minimum number, size, and quality of economically viable deposits at various confidence levels and (2) a map of where these deposits may exist.

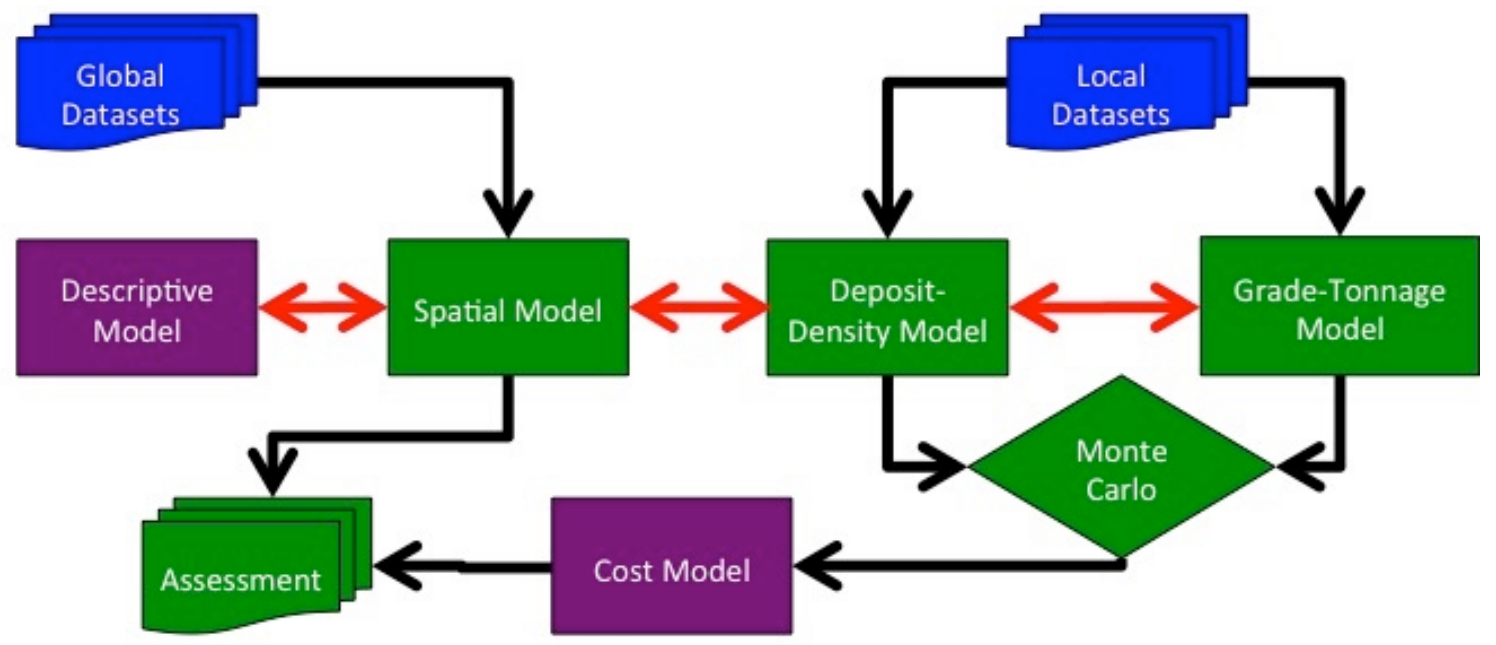

Figure 1. Flowchart for USGS resource assessments. Blue boxes are datasets, green boxes derive from USGS processes with minor modification, and purple boxes require some conceptual adjustments to apply to Solar System exploration and science. Black arrows represent the flow of information. Red arrows indicate iteration and research.

\section{Descriptive Model for Asteroids}

The first part of an assessment is to describe the geologic settings in which concentrations of the relevant resource can be found. Each geologic setting on Earth has a characteristic mineral assemblage. For asteroids, this emphasis on petrology is similar to meteorite classes. To link meteorites to asteroids, we rely on the Small Main-belt Asteroid Spectroscopic Survey (SMASS) taxonomy (Binzel and others, 2004). For this feasibility study, we simplify the problem by only considering the three main spectral 
categories (C, S, and X). We further simplify matters by equating $\mathrm{C}$ asteroids with carbonaceous chondrites, $\mathrm{X}$ asteroids with iron meteorites and pallasites, and $\mathrm{S}$ asteroids with all other meteorites (which are mostly stony). This simple translation from spectral data to meteorite type is a gross oversimplification that ignores many important categories of asteroid spectra and types of meteorites. In fact, we are aware of a few cases where this oversimplification associates an asteroid with the wrong type of meteorite. However, it is sufficient to demonstrate the general approach that could be used in a real assessment of asteroid resources. Some key steps needed to provide more reliable input to an assessment are discussed at the end of this report.

\section{Spatial Model for Asteroids}

The first quantitative model, the spatial model, describes where ore bodies can be found within boundaries set by political and technical limits. In our case, each asteroid can be thought of as an ore body. We limit this initial analysis to NEOs based on change in velocity $(\Delta v)$, a measure of the effort needed to move between two objects (or orbits) in space. We limit our analysis to objects that can be reached from low Earth orbit with a $\Delta v$ of $\leq 7$ kilometers per second $(\mathrm{km} / \mathrm{s})$, which includes most objects between Earth and Mars, but excludes the main-belt asteroids. The objects and their orbital parameters are taken from the Minor Planet Center database (minorplanetcenter.net) and $\Delta v$ is calculated using the methods of Shoemaker and Helin (1978). We prefer to analyze NEOs, with their slightly more generic definition than near-Earth asteroids (NEA), because they can include remnants of comets.

\section{Deposit-Density Model for Near-Earth Objects}

The second model, the deposit-density quantitative model, is used to determine how many deposits (that is, asteroids) are in the study area. This part of the assessment takes advantage of activities driven by the George E. Brown, Jr. Near-Earth Object Survey Act of 2005 that requires the National Aeronautics and Space Administration (NASA) to identify $\geq 90$ percent of potentially hazardous NEAs greater than 140 meters in diameter. The catalog of NEAs with diameters greater than $1 \mathrm{~km}$ is now 9095 percent complete, but there are differing estimates on how many smaller bodies remain undiscovered (for example, Mainzer and others, 2011; Stuart and Binzel, 2004). However, because more than 99 percent of the volume of NEAs is in objects $\geq 1 \mathrm{~km}$ in diameter (fig. 2 ), we are able to ignore the smaller asteroids for this initial assessment. 


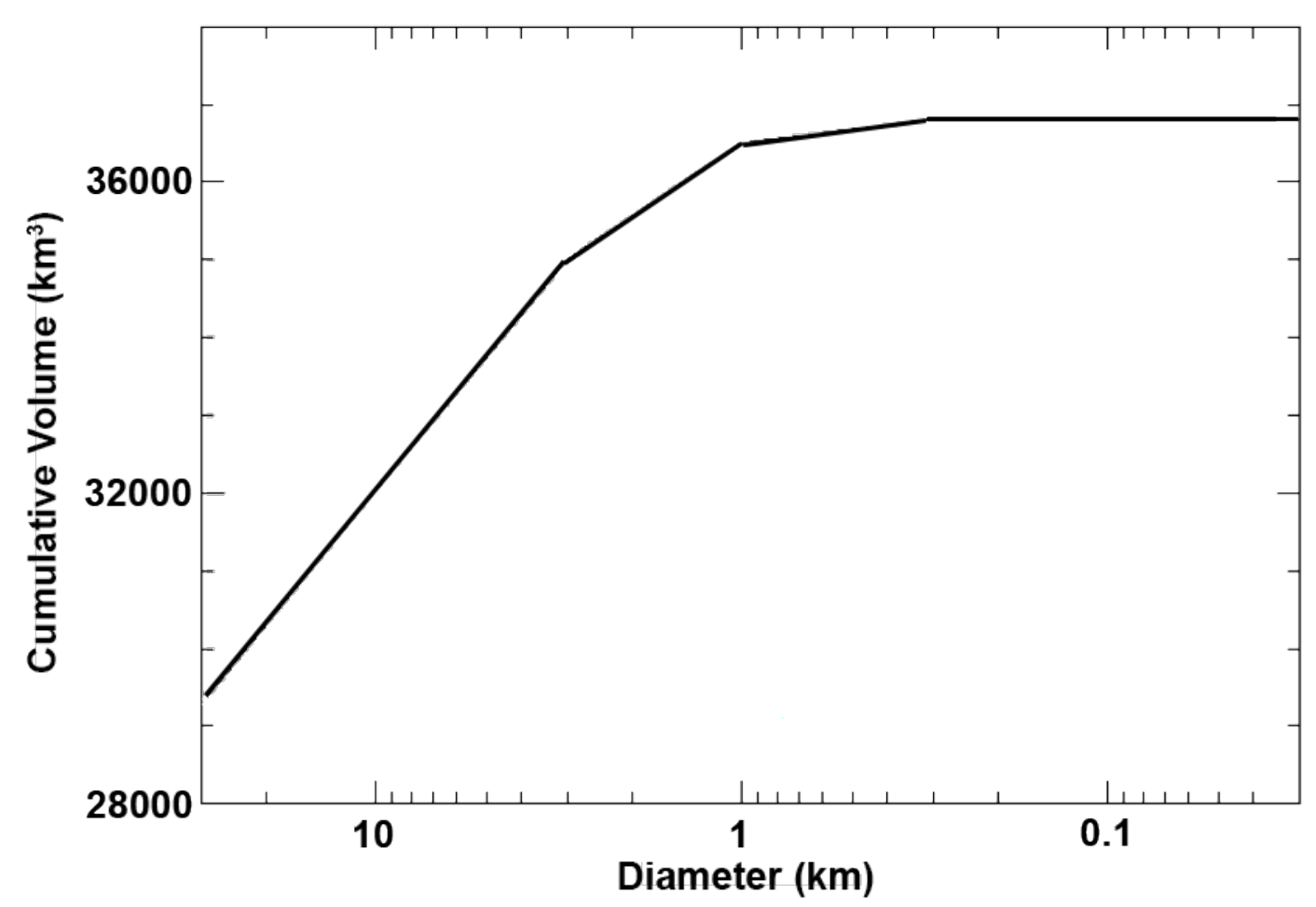

Figure 2. Cumulative volume of near-Earth objects (NEOs) versus NEO diameter calculated from observed brightness.

\section{Grade-Tonnage Model for Near-Earth Objects}

For NEOs, we divide the third quantitative model into its two components. The "tonnage" part describes the size distribution of deposits (that is, asteroids). Whereas there are some questions about the size distribution of the smaller bodies, the $\geq 1 \mathrm{~km}$ diameter objects are well characterized (fig. 2). However, there are significant uncertainties in the mass represented by these bodies, especially because the densities of asteroids are highly variable and difficult to estimate (Chesley and others, 2002).

The final quantitative model we use describes the probability distribution of the quality (that is, grade) of the deposit. Resource quality is primarily governed by the concentration of the resource, but is also secondarily affected by how the resource is bound in the rock. Native iron-nickel alloys make up nearly all of metallic asteroids and as much as 25 percent of carbonaceous chondrites. The primary source of uncertainty is that only 5-20 percent of the asteroids in the X spectral group are actually metallic (Thomas and others, 2011).

For water, we do not expect pure water ice to be found on NEOs in any meaningful concentration. Instead, we focus on hydrated minerals. Whereas some primitive carbonaceous chondrites have more than 20 percent by weight bound water, most have been heated sufficiently to contain only a few percent water (Mason, 1963). Furthermore, the concentration can vary significantly with depth if an asteroid has been heated for a geologically short time. Because of processes that affect meteorites as they pass through the Earth's atmosphere and while they sit on the Earth's surface, there may be a sample bias against the most primitive chondritic bodies in the meteorite collection. In other words, there are significant issues, and thus large uncertainties, in estimating the water content of carbonaceous asteroids from samples in the meteorite collection. 


\section{Modeling}

The final step is to combine the models in a statistically rigorous manner to obtain the total amount of each resource expected at the 10, 50, and 90 percent exceedance quantiles. Because the statistical distributions in the locations, sizes, and compositions of ore bodies (and asteroids) do not fit simple statistical models, it has proven necessary to utilize Monte Carlo methods to do this combination correctly. For this step, we created a simple Monte Carlo model in FORTRAN that we have named ASTRA1. The code for ASTRA1 is included as appendix 1 of this publication.

As input, we start with the list of known asteroids with $\Delta v$ less than $7 \mathrm{~km} / \mathrm{s}$ and absolute magnitude $\left(\mathrm{M}_{\mathrm{H}}\right)$ brighter than 18, which approximately corresponds to a diameter of $1 \mathrm{~km}$ for dark objects. Figure 3 shows the distribution of the brightness of the 428 objects in this list. Because this list may be only 90 percent complete, an additional 43 entries are added with their $\mathrm{M}_{\mathrm{H}}$ coded as " 0 ". This is our deposit-density model.

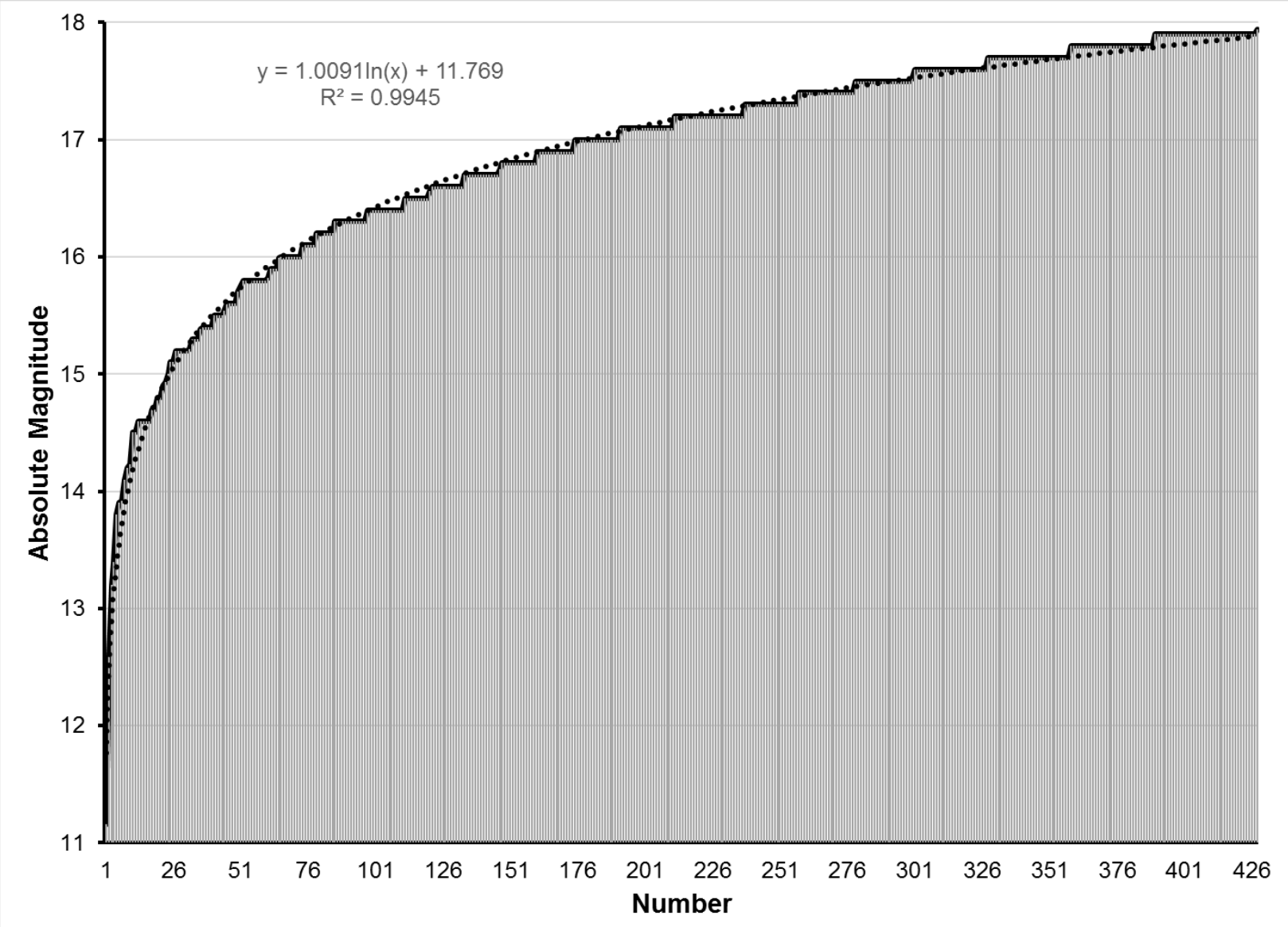

Figure 3. Cumulative distribution function of absolute magnitude $\left(\mathrm{M}_{H}\right)$ of the 428 known objects with $\Delta v$ less than $7 \mathrm{~km} / \mathrm{s}$ included in this study. The logarithmic fit is used to obtain brightness values for the undiscovered objects also included in this study.

For composition, we rely on the SMASS spectral classification from Binzel and others (2004) and relate spectral class to meteorite group as described in table 1 . Of the 428 asteroids listed, 8 are annotated as metal-rich, 16 as carbonaceous, and 76 as stony. The remainder could not be matched to an object in Binzel and others (2004) and were classified as unknown with a numerical code of " 0 ". The input data file is provided as appendix 2 of this publication. 
Table 1. Association among spectral types and meteorite groups in this study.

\begin{tabular}{|l|l|l|}
\hline \multicolumn{1}{|c|}{ Assumed Meteorite Group } & \multicolumn{1}{|c|}{$\begin{array}{c}\text { SMASS Spectral Type from } \\
\text { Binzel and others (2004) }\end{array}$} & Numerical Value in input file \\
\hline Stony & $\begin{array}{c}\text { A, K, K:, L, Ld, O, Q, R, S, S:, S(IV), Sa, Sk, Sl, } \\
\text { Sq, Sq:, Sr, U, V, V: }\end{array}$ & 1 \\
\hline Carbonaceous & B, C, C:, Cb, Cg, Ch, D, T & 2 \\
\hline Metal-rich & X, X:, Xc, Xe, Xk, & 3 \\
\hline
\end{tabular}

We ran 100,000 cases through ASTRA1 to investigate the range of water and metal that might be available in the NEO population. Here, we explain the steps used to generate each of these possible cases.

First, a brightness $\left(\mathrm{M}_{\mathrm{H}}\right)$ was assigned to each of the 43 potential undiscovered objects. Figure 3 shows the brightness distribution of the 428 known objects and a logarithmic fit to those data. The undiscovered objects are assumed to have the same brightness distribution as the known objects. This is incorrect because the undiscovered objects will be biased toward being fainter than the known objects (since brighter objects are easier to discover). Furthermore, because the survey on large NEOs may be 95 percent complete, we assign each of the potential undiscovered objects a 50 percent chance to not exist. Numerically, this is done by giving a non-existent object an $\mathrm{M}_{\mathrm{H}}$ of 100 , making them far too small to affect subsequent calculations.

Next, for the objects that were not spectrally classified, a composition was assigned randomly with a probability of 39 percent to be stony, 27 percent to be carbonaceous, and 34 percent to be metalrich. These are the proportions found in the broader NEO population reported in Binzel and others (2004) and bias-corrected by Stuart and Binzel (2004). The bias is significant because spectra are much easier to obtain for the brighter (typically stony) objects. The raw (that is, biased) proportions for the known objects in our list with SMASS spectra are 83 percent stony, 8 percent carbonaceous, and 9 percent metal-rich. Given the relatively small number of objects with SMASS spectra, the magnitude of this bias is unsurprising. However, it is important to note that there are more infrared spectra of asteroids available today than are included in Binzel and others (2004). A proper assessment of asteroid resources would need to take all those data into account, but the data we use are sufficient to demonstrate the feasibility of the approach we are taking.

In the software, the next step is to calculate the mass of each object. The brightness is converted to diameter using the relationship from Harris and Harris (1997). There is insufficient data to determine empirical probability distribution functions for the albedos of NEOs. Canonical values for albedo are about 5 percent for carbonaceous objects and about 20 percent for other asteroids. Whereas better information is available for some objects, we simulate uncertainty in these canonical albedo values by varying them by \pm 50 percent with a simple linear distribution.

Carry (2012) conducted an extensive study of various physical properties of asteroids, including density. The tabulated information for each spectral class is condensed into the three compositions we consider in table 2. In the ASTRA1 program we assume a simple linear distribution between the minimum and maximum densities. An alternative, and possibly more self-consistent, method for estimating density would be to use values obtained for each meteorite class (for example, Consolmagno and others, 2008 but the differences in values are small (nearly 10 percent). 
Table 2. Density range for each composition group derived from data compiled by Carry (2012). $\left[\mathrm{kg} / \mathrm{m}^{3}\right.$, kilogram per cubic meter]

\begin{tabular}{|l|c|l|l|}
\hline Composition Group & $\begin{array}{c}\text { Minimum Density } \\
\left(\mathrm{kg} / \mathrm{m}^{3}\right)\end{array}$ & $\begin{array}{c}\text { Mean Density } \\
\left(\mathrm{kg} / \mathrm{m}^{3}\right)\end{array}$ & $\begin{array}{c}\text { Maximum Density } \\
\left(\mathrm{kg} / \mathrm{m}^{3}\right)\end{array}$ \\
\hline Stony & 1468 & 2704 & 3940 \\
\hline Carbonaceous & 577 & 2086 & 3595 \\
\hline Metal-rich & 1391 & 3482 & 5574 \\
\hline
\end{tabular}

From diameter and density, it is straightforward to calculate the mass of each object, assuming that they are spheres. While asteroids are not spherical, the method for calculating diameter gives an effective diameter that results in errors much smaller than the other uncertainties we have already discussed. This completes the tonnage part of the grade-tonnage model.

For our grade model, we use the compositional data from Nittler and others (2004). We consider only whole-rock analyses and are only interested in the metallic iron (FE_M in their tables) and hydrogen concentrations. We multiply the hydrogen concentration by 9 to obtain the mass of water instead of hydrogen. In asteroids, hydrogen may mostly exist in the form of hydroxyl $(\mathrm{OH})$ but we assume the extraction technology will convert this to water (the "waste" product would be oxygenitself a potentially desirable resource, but one we do not examine in this report). Table 3 shows the meteorite classes that were included in each of our composition groups. Figure 4 shows the distribution of metallic iron and water concentrations for each of the three composition groups and the empirical expressions fit to them. In ASTRA1, the metallic iron and water concentration is randomly selected for each object using these mathematical expressions.

Table 3. Mapping among compositional groups for this study and meteorite classes from Nittler and others (2004).

\begin{tabular}{|l|l|}
\hline \multicolumn{1}{|c|}{ Compositional Group } & \multicolumn{1}{c|}{ Meteorite Classes from Nittler and others (2004) } \\
\hline Stony & $\begin{array}{l}\text { ACA, ANG, AUB, BENC, DIO, E, EH, EL, EUC, H, HOW, L, L/LL, LL, LOD, } \\
\text { LUN, R SHE, URE }\end{array}$ \\
\hline Carbonaceous & C, CI, CK, CM, CO, CR, CV \\
\hline Metal-rich & IAB, IIE, MES, PALL \\
\hline
\end{tabular}



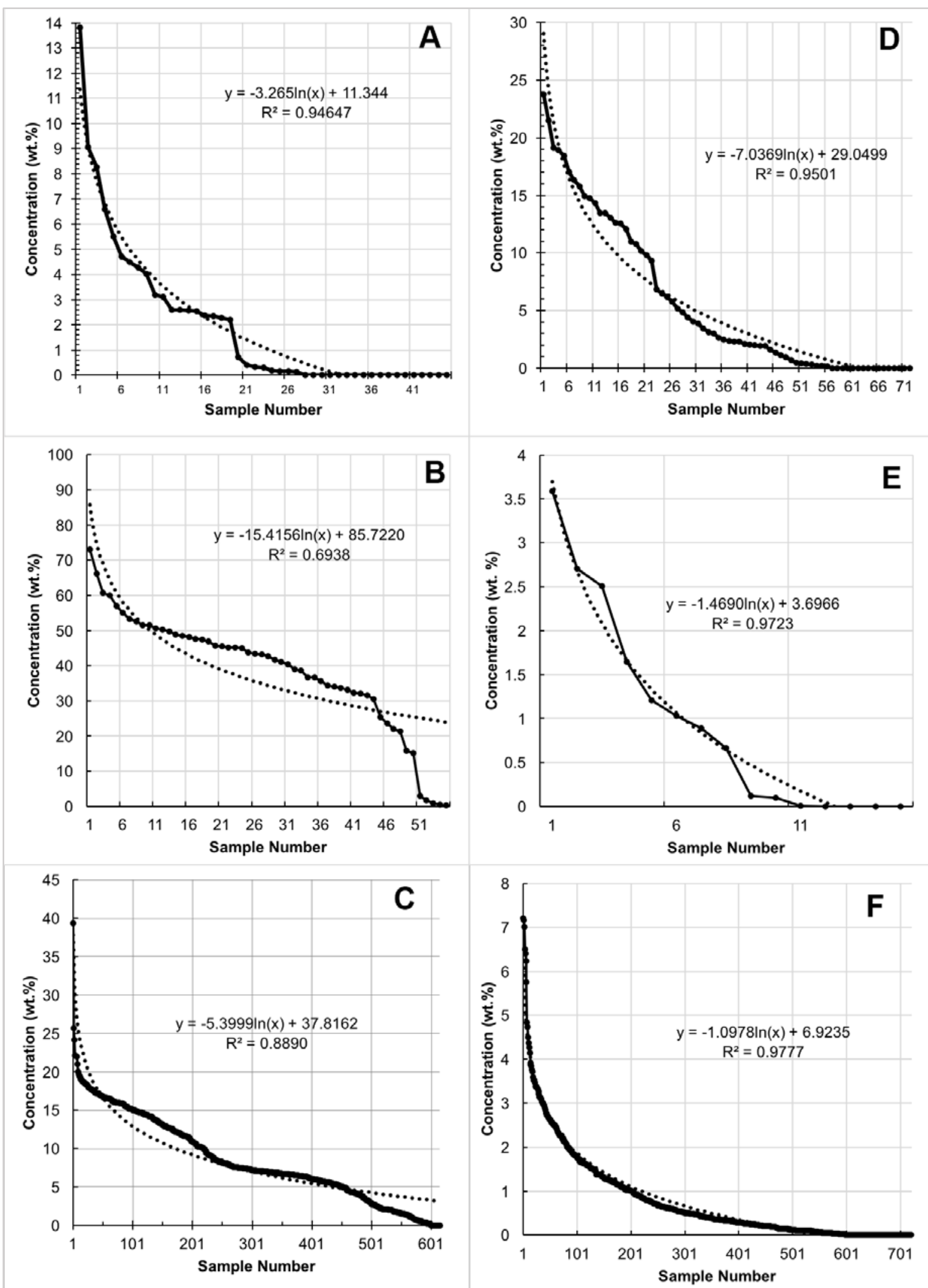

Figure 4. Curve fits (dotted lines) to the meteorite composition compilation of Nittler and others (2004; line with black circles). Iron and water concentrations, in percent by weight (wt. \%), are shown for the three major meteorite 
categories as described in table 3. (A) Iron-nickel alloy in carbonaceous meteorites, (B) iron-nickel alloy in metalrich meteorites, (C) iron-nickel alloy in stony meteorites, (D) water in carbonaceous meteorites, (E) water in metalrich meteorites, and $(\mathrm{F})$ water in stony meteorites.

There remain serious questions about how representative these data are of the compositions of meteorites. Additionally, there are further serious questions about how representative meteorites are of the NEO population. We do not address these issues in this feasibility study.

The final step in ASTRA1 is to sum the amounts of free metallic iron and water in the entire simulated NEO population. To facilitate obtaining statistics, the 100,000 runs are sorted and summaries are output. The results are presented in the next section.

\section{Discussion}

Figure 5 shows the probability distribution of water and metallic iron expected based on the parameters discussed above. The information is summarized in table 4 .

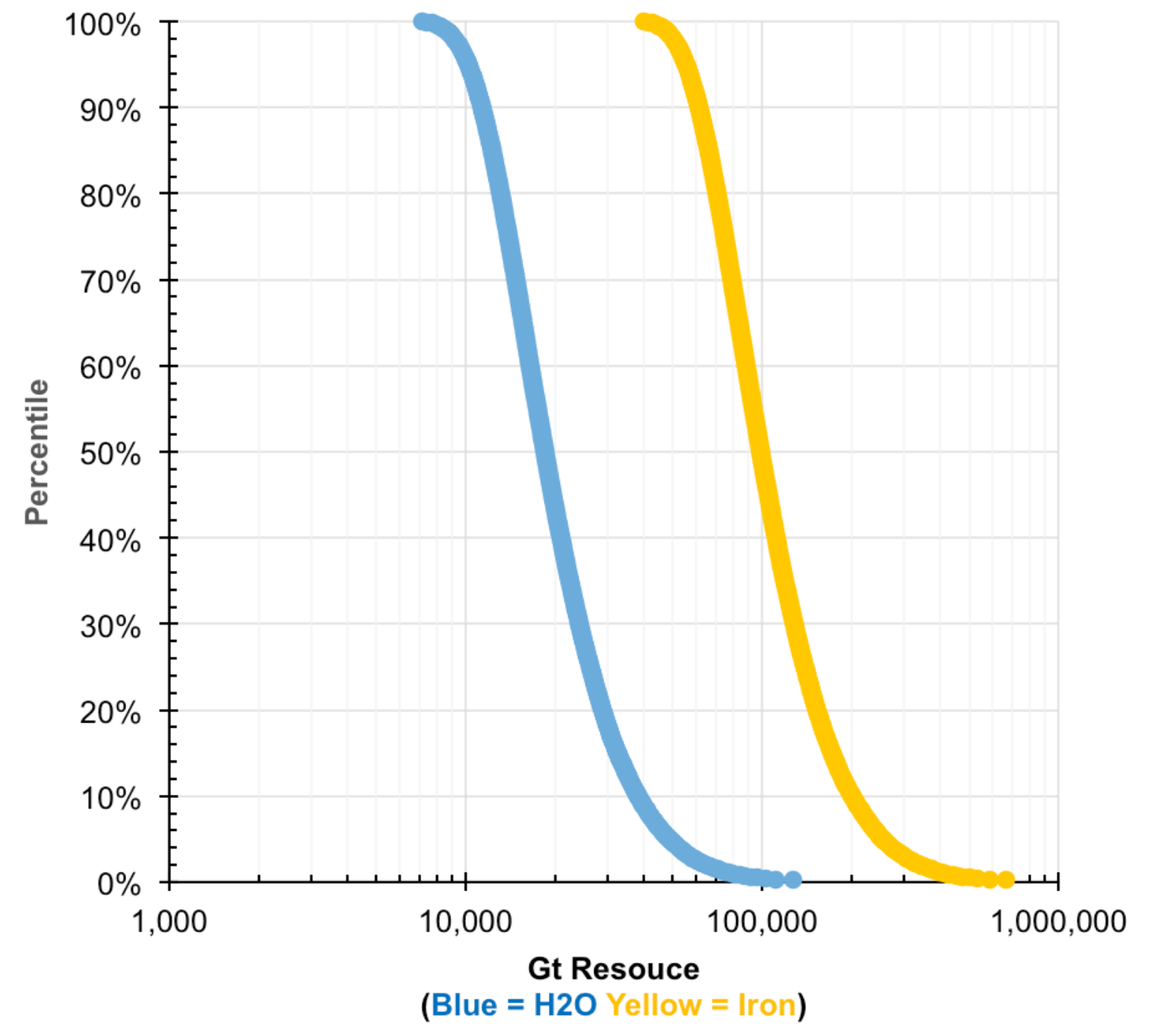

Figure 5. Output of ASTRA1 modeling showing how the minimum amount of water and metallic iron resources (in gigatons, Gt) in near-Earth objects would be represented in a USGS resource assessment. 
Table 4. Minimum amount of water and metallic iron resources in near-Earth objects.

[Gt, gigatons]

\begin{tabular}{|l|l|l|l|}
\hline & \multicolumn{1}{|c|}{$\mathbf{9 0 \%}$ probability (Gt) } & $\mathbf{5 0 \%}$ probability (Gt) & \multicolumn{1}{|c|}{$\mathbf{1 0 \%}$ probability (Gt) } \\
\hline Water & 11,000 & 18,000 & 38,000 \\
\hline Metallic iron & 61,000 & 99,000 & 200,000 \\
\hline
\end{tabular}

On face value, these results suggest we have assessed the likely amount of resources available in NEOs to about a factor of 4 . However, we reiterate that the objective of this study was not to produce an accurate and reliable assessment of NEO resources. As we have discussed, there are major sources of uncertainty that are incorrectly modeled or not included at all. For example, the linkage between spectral classes and meteorite groups is assumed to be perfect when we know it is a gross oversimplification. It is plausible that values presented in table 4 and figure 5 may be off by a factor of a hundred or more.

Even given these caveats, it is clear that the amount of useful resources in NEOs is immense when compared to current needs. For example, the International Space Station has a mass of less than 400 tons and the crew of 6 uses about 5 tons of water per year. The numbers in table 4 could sustain a million-fold increase in human activity in space for a million years. Even if the numbers are too large by a factor of a thousand, or even a million, there appears to be a significant amount of useful resources in NEOs.

Of course, one must also consider humanity's ability to extract those resources. Based on the technology that is deployed in space as of this writing, the amount of extractable water and metallic iron in NEOs is known with great certainty to be zero. The immense promise of NEO mineral resources is currently untappable. Unsurprisingly, there are a number of efforts underway to change that.

As resource extraction technology is developed, the actual amount of usable resources in NEOs is likely to increase slowly. For example, if water is extracted by putting an entire asteroid in a plastic bag, the km-scale objects we focused on in this feasibility study would be useless. Instead, the focus would need to be on much smaller objects, perhaps only tens of meters across. Those small objects constitute a miniscule fraction of the volume of all NEOs, but they may be sufficient to enable human space activities for decades or centuries to come.

To be economically viable, processed and delivered asteroid resources would need to cost less than having the same need supplied from Earth. For reference, the cost of platinum on Earth has been about \$30,000 per kilogram (kg) in recent years. The cost of water and base metals is trivial on Earth, but transporting them to users in space is expensive. The nearly $\$ 200$-million Atlas V launch of the Mars Science Laboratory put just over 3,000 kg on a transfer orbit to Mars, suggesting a cost in the ballpark of $\$ 50,000 / \mathrm{kg}$ for water (or any other resource) to support a human crew traveling to Mars. It is worth emphasizing that the USGS does not assess the technologies or economics of resource extraction. Instead, the USGS assessment supplies the input data for others who examine those types of issues.

None of these issues should detract from the fundamental point of this study. We have successfully demonstrated that the USGS resource assessment methods can be applied to asteroids. The natural next question concerns what is needed to do a proper assessment. Modest improvements can be made by correcting some simplifying assumptions and using additional datasets we did not incorporate into this feasibility study. However, there are key sources of uncertainty that require new fundamental scientific research. We have identified three areas of research that are needed to produce an accurate and reliable assessment of NEO resources.

First, too few NEOs have high-quality spectral observations, especially in the mid-infrared range. This is especially true for the smaller objects that are more likely to be targets for initial resource extraction. At the same time, this feasibility study does not make full use of all the data that are 
currently available. For example, in the absence of full infrared spectra, even basic albedo data can provide some useful constraints on the composition of an asteroid.

Second, our ability to link spectral classes of asteroids to meteorite samples is tenuous. Returned samples from asteroids are the best way to ground-truth these linkages. However, it is unrealistic to expect returned samples from a statistically significant portion of the NEO population. It is important to support the study of returned samples with spectral classification of meteorites (and analog materials) in realistic settings. This requires laboratory measurements of appropriate materials in vacuum, at a range of temperatures, subjected to the radiation environment in space, and with a range of realistic particle sizes. Even with improved spectral libraries, telescopic observations from Earth will have limited ability to positively identify the composition of the asteroid underneath the weathered surficial layer. Missions that analyze the composition of asteroids at a depth of at least several centimeters are essential. One possible way to accomplish this is a fleet of small spacecraft that insert reusable probes into many locations on multiple asteroids, as suggested by Asphaug and others (2017).

Finally, attempts to collate the available compositional and mineralogical data for meteorite samples have highlighted important deficiencies in this critical dataset (for example, Nittler and others, 2004). It is always difficult to compare results from different laboratories using different techniques over the span of many decades. Furthermore, most research on meteorites is focused on specific scientific problems that do not require comprehensive knowledge or data for the entire meteorite-the ratios of a few elements, or even just isotopes of a key element, suffice. Thus, there is a need for systematic and consistent whole-rock and modal-mineralogy analyses of meteorites.

\section{References Cited}

Asphaug, E., Baker, J., Choukroun, M., Furfaro, R., Sava, P., Scheeres, D.J., Schwartz, S.R., Swindle, T., and Thangavelautham, J., 2017, Spacecraft penetrator for increasing knowledge of NEOs (SPIKE) [abs.]: Lunar and Planetary Science Conference XLVIII Abstract with Program, no. 1981, 2 p.

Binzel R.P., Rivkin A.S., Stuart, J.S., Harris A.W., Bus S.J., and Burbine, T.H., 2004, Observed spectral properties of near-Earth objects—results for population distribution, source regions, and space weathering processes: Icarus, v. 170, p. 259-294.

Carry, B., 2012, Density of asteroids: Planetary and Space Science, v. 73, p. 98-118.

Chesley S.R., Chodas, P.W., Milani, A., Valsecchi, G.B., and Yeomans, D.K., 2002, Quantifying the Risk Posed by Potential Earth Impacts: Icarus, v. 159, p. 423-432.

Consolmagno, G.J., Britt, D.T., and Macke, R.J., 2008, The significance of meteorite density and porosity: Chemie der Erde-Geochemistry, v. 68, p. 1-29.

Gerlach C.L., 2005, Profitably exploiting near-Earth object resources: National Space Society, papers of the 2005 International Space Development Conference, 56 p., accessed April 5, 2017, at https://pdfs.semanticscholar.org/6793/565ed499d7056a451379a71bdba3478f0012.pdf.

Harris A.W., and Harris, A.W., 1997, On the Revision of Radiometric Albedos and Diameters of Asteroids: Icarus, v. 126, p. 450-454.

Lewis J.S., 2014, Asteroid Mining 101-Wealth for the New Space Economy: Deep Space Industries, $192 \mathrm{p}$.

Mainzer, A., Grav, T., Bauer, J., Masiero, J., McMillan, R.S., Cutri, R.M., Walker, R., Wright, E., Eisenhardt, P., Tholen, D.J., Spahr, R., Jedicke, R., Denneau, L., DeBaun, E., Elsbury, D., Gautier, T., Gomillion, S., Hand, E., Mo, W., Watkins, J., Wilkins, A., Bryngelson, G.L., Del Pino Molina, A., Desai, S., Gómez Camus, M. Hidalgo, S.L., Konstantopoulos, I., Larsen, J.A., Maleszewski, C., Malkan, M.A., Mauduit, J-C., Mullan, B.L., Olszewski, E.W., Pforr, J., Saro, A., Scotti, J.V., and 
Wasserman, L.H., 2011, NEOWISE observations of near-Earth objects-Preliminary results: Astrophysical Journal, v. 743, 17 p.

Mason B., 1963, The carbonaceous chondrites: Space Science Reviews, v. 1, p. 621-646.

Nittler L.R., McCoy, T.J., Clark, P.E., Murphy, M.E., Trombka, J.I., and Jarosewich, E., 2004, Bulk element compositions of meteorites - a guide for interpreting remote-sensing geochemical measurements of planets and asteroids: Antarctic Meteorite Research, v. 17, p. 233-253.

Ostro S.J., Cambell, D.B., Chandler, J.F., Hine, A.A., Hudson, R.S., Rosema, K.D., and Shapiro, I.I., 1991, Asteroid 1986 DA—Radar Evidence for a Metallic Composition: Science, v. 252, p. 13991404.

Shoemaker, E.M. and Helin, E.F., 1978, Earth-approaching asteroids as targets for exploration, in Asteroids-An exploration assessment: NASA Conference Publication 2053, p. 245-256.

Singer D.A., 2007, Short course introduction to quantitative mineral resource assessments: U.S. Geological Survey Open-File Report 2007-1434, 13 p.

Stuart J.S. and Binzel, R.P., 2004, Bias-corrected population, size distribution, and impact hazard for the near-Earth objects: Icarus, v. 170, p. 295-311.

Thomas C.A., Trilling, D.E., Emery, J.P., Mueller, M., Hora, J.L., Benner, L.A.M., Bhattacharya, B., Bottke, W.F., Chesley, S., Delbo, M., Fazio, G., Harris, A.W., Mainzer, A., Mommert, M., Morbidelli, A., Penprase, B., Smith, H.A., Spahr, T.B., and Stansberry, J.A., 2011, ExploreNEOs. V. Average albedo by taxonomic complex in the near-Earth asteroid population: Astronomical Journal, v. $142,12 \mathrm{p}$. 


\title{
Appendix 1. ASTRA1.f
}

\author{
REAL R,A(500,10),ABS,ABC,ABM,AB,Ro,D \\ REAL PI,HTOT,FETOT,CH,CFE,OUT(1000,2),X \\ REAL WORK $(100000,2), \operatorname{SORT}(100000,2)$ \\ INTEGER N,M,J
}

c $\mathrm{A}\left({ }^{*}, 1\right)=$ brightness (Magnitude)

c $A\left({ }^{*}, 2\right)=$ SMASS class $(0=$ unknown, $1=S, 2=C, 3=M)$

c $A(*, 3)=$ volume $(\mathrm{km} 3)$

c $A(*, 4)=\operatorname{mass}(\mathrm{Gt})$

c $A\left({ }^{*}, 5\right)=\mathrm{dV}(\mathrm{km} / \mathrm{s})$

c $\mathrm{A}\left({ }^{*}, 6\right)=$ mass $\mathrm{H} 2 \mathrm{O}(\mathrm{Gt})$

C $\mathrm{A}\left({ }^{*}, 7\right)=$ mass metal $(\mathrm{Gt})$

c $A(*, 8)=$ not used

C $A(*, 9)=$ brightness with guesses for undiscovered asteroids

c $A(*, 10)=$ spectral class with guesses for unknowns

C Set constants

$\mathrm{PI}=3.1415926589$

C Set mean albedo for S, C, and M

ABS $=0.20$

$A B C=0.05$

$\mathrm{ABM}=0.20$

C Initialize random number generator

WRITE $\left({ }^{*},{ }^{*}\right)$ 'Hello'

WRITE $\left({ }^{*},{ }^{*}\right)$ 'Please give me an integer?'

$\operatorname{READ}(*, *) \mathrm{M}$

DO $\mathrm{N}=1, \mathrm{M}$

CALL RANDOM_NUMBER(R)

\section{END DO}

C Read input file

OPEN(UNIT=1,FILE="ASTRA_INPUT.cSV",STATUS="OLD")

DO $N=1,471$

$\operatorname{READ}(1, *) A(N, 5), A(N, 1), A(N, 2)$

END DO

CLOSE(UNIT=1)

c Run the model 100,000 times

WRITE $\left({ }^{*},{ }^{*}\right)$ 'Starting the 100,000 runs'

DO $M=1,100000$

C Reset total $\mathrm{H}$ and Fe to zero

$\mathrm{HTOT}=0$.

FETOT $=0$.

C Start work on asteroid input data

$\mathrm{DO} \mathrm{N}=1,471$

C Add asteroids we have not detected yet (50\% chance they exist)

IF(A(N,1).EQ.0) THEN

CALL RANDOM_NUMBER(R)

IF(R.LT.0.5) THEN

$A(N, 9)=100$.

ELSE

$A(N, 9)=\left(1.0091^{*} \operatorname{LOG}\left(R^{*} 428\right)\right)+11.769$

ENDIF

ELSE

$\mathrm{A}(\mathrm{N}, 9)=\mathrm{A}(\mathrm{N}, 1)$ 
c Add spectral class for asteroids that don't have observations

c Relative abundance of C, S, and X from Stuart J. S and Binzel R. P. (2004).

c Bias-corrected population, size distribution and impact hazard for near-Earth

c objects. Icarus 170, 295-311.

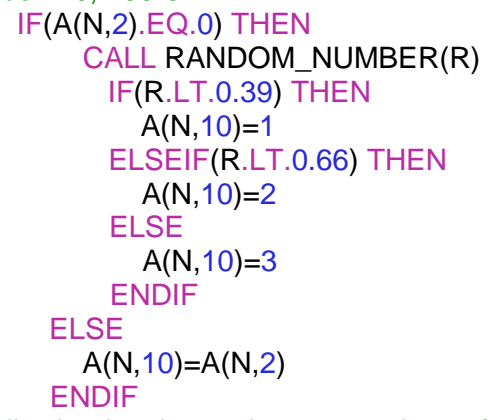

c Generate albedo, density, and concentrations of $\mathrm{H}$ and $\mathrm{Fe}$ IF(A $(N, 10)$. 1$)$ THEN

CALL RANDOM_NUMBER(R) $A B=A B S^{*}(0.5+R)$

CALL RANDOM_NUMBER(R)

$\mathrm{Ro}=1.468+(\mathrm{R} * 2 . \overline{4} 72)$

CALL RANDOM_NUMBER(R)

$\mathrm{X}=\mathrm{R} * 720$.

$\mathrm{CH}=(-1.098 * \mathrm{LOG}(\mathrm{X}))+6.9235$

IF(CH.LT.0) $\mathrm{CH}=0$.

CALL RANDOM_NUMBER(R)

$\mathrm{X}=\mathrm{R} * 615$.

CFE $=(-5.3999 * \operatorname{LOG}(\mathrm{X}))+37.8162$

IF(CFE.LT.0) CFE=0.

ENDIF

IF $(\mathrm{A}(\mathrm{N}, 10)$. EQ.2) THEN

CALL RANDOM_NUMBER(R)

$A B=A B C *(0.5+R)$

CALL RANDOM_NUMBER(R)

$\mathrm{Ro}=0.577 *(\mathrm{R} * 3 . \overline{0} 17)$

CALL RANDOM_NUMBER(R)

$\mathrm{X}=\mathrm{R} * 72$.

$\mathrm{CH}=(-7.037 * \mathrm{LOG}(\mathrm{X}))+29.05$

IF(CH.LT.0) $\mathrm{CH}=0$.

CALL RANDOM_NUMBER(R)

$X=R * 45$.

CFE $=(-3.265 * \operatorname{LOG}(X))+11.344$

IF(CFE.LT.0) CFE $=0$.

ENDIF

IF(A(N,10).EQ.3) THEN

CALL RANDOM_NUMBER(R)

$A B=A B M^{*}(0.5+R)$

CALL RANDOM_NUMBER(R)

$\mathrm{Ro}=1.391+(\mathrm{R} * 4.183)$

CALL RANDOM_NUMBER(R)

$\mathrm{X}=\mathrm{R} * 15$.

$\mathrm{CH}=(-1.469 * \mathrm{LOG}(\mathrm{X}))+3.6966$

IF(CH.LT.0) $\mathrm{CH}=0$.

CALL RANDOM_NUMBER(R)

$\mathrm{X}=\mathrm{R} * 55$.

CFE $=(-0.001276 *(X * 3))+(0.09227 *(X * * 2))-(2.56 * X)+69.64$

IF(CFE.LT.0) CFE $=0$.

ENDIF

C Calculate diameter, volume, and masses

$D=1329 *(10 * *(-0.2 * A(N, 9))) /\left(A B^{* *} 0.5\right)$

$\mathrm{A}(\mathrm{N}, 3)=4^{*} \mathrm{PI} *\left((\mathrm{D} / 2 .)^{* * 3}\right) / 3$.

$\mathrm{A}(\mathrm{N}, 4)=\mathrm{Ro}^{\star} \mathrm{A}(\mathrm{N}, 3)$

$\mathrm{A}(\mathrm{N}, 6)=\mathrm{A}(\mathrm{N}, 4)^{*} \mathrm{CH}$ 
$A(N, 7)=A(N, 4)^{\star} C F E$

C Add amount of $\mathrm{H}$ and $\mathrm{Fe}$ to the running total

$\mathrm{HTOT}=\mathrm{HTOT}+\mathrm{A}(\mathrm{N}, 6)$

FETOT=FETOT+A(N,7)

END DO

WRITE $(*, *)$ 'RUN ',M

$\operatorname{WORK}(\mathrm{M}, 1)=\mathrm{HTOT}$

WORK $(M, 2)=F E T O T$

END DO

C Sort output

WRITE $\left({ }^{*},{ }^{*}\right)$ 'Starting to sort'

$\operatorname{SORT}(1,1)=\operatorname{WORK}(1,1)$

$\operatorname{SORT}(1,2)=\operatorname{WORK}(1,2)$

DO $M=2,100000$

WRITE $\left({ }^{*},{ }^{*}\right)$ 'SORTING POSITION ',M

DO N=1,M-1

IF(WORK(M,1).LT.(SORT(N,1))) THEN

DO J=M,N+1,-1

END DO

$\operatorname{SORT}(\mathrm{J}, 1)=\operatorname{SORT}(\mathrm{J}-1,1)$

$\operatorname{SORT}(\mathrm{N}, 1)=\operatorname{WORK}(\mathrm{M}, 1)$

GOTO 100

ELSE

$\operatorname{SORT}(M, 1)=\operatorname{WORK}(M, 1)$

END DO

100 CONTINUE

DO N=1,M-1

IF(WORK(M,2).LT.(SORT(N,2))) THEN

DO $\mathrm{J}=\mathrm{M}, \mathrm{N}+1,-1$

END DO

$\operatorname{SORT}(\mathrm{J}, 2)=\operatorname{SORT}(\mathrm{J}-1,2)$

$\operatorname{SORT}(\mathrm{N}, 2)=\operatorname{WORK}(\mathrm{M}, 2)$

GOTO 200

ELSE

$\operatorname{SORT}(M, 2)=W O R K(M, 2)$

END DO

200 CONTINUE

END DO

C Output

DO $M=1,1000$

$\operatorname{OUT}(\mathrm{M}, 1)=\operatorname{SORT}\left(\mathrm{M}^{\star} 100,1\right)$

$\operatorname{OUT}(\mathrm{M}, 2)=\operatorname{SORT}\left(\mathrm{M}^{\star} 100,2\right)$

WRITE $\left(7,{ }^{*}\right)$ OUT(M,1),OUT(M,2)

END DO

WRITE $\left({ }^{*},{ }^{*}\right)$ '90\% chance of exceeding ',OUT(100,1),' Gt of H2O' WRITE $\left({ }^{*}, *\right) ' 50 \%$ chance of exceeding ',OUT $(500,1),{ }^{\prime}$ ' Gt of H2O' WRITE $\left({ }^{*},{ }^{*}\right) ' 10 \%$ chance of exceeding ',OUT $(900,1)$,' Gt of H2O' WRITE $\left(*,{ }^{*}\right)$ '90\% chance of exceeding ',OUT $(100,2)$, ' Gt of metal' WRITE(*,*)'50\% chance of exceeding ',OUT $(500,2)$, ' Gt of metal' WRITE $(*, *) ' 10 \%$ chance of exceeding ',OUT $(900,2)$, ' Gt of metal'

END 


\section{Appendix 2. ASTRA_INPUT.csv}

$\begin{array}{rrr}5.188 & 11.16 & 1 \\ 6.968 & 15.5 & 1 \\ 6.503 & 13.4 & 0 \\ 5.816 & 17.7 & 0 \\ 5.482 & 15.6 & 1 \\ 5.87 & 13.2 & 1 \\ 6.135 & 14.23 & 1 \\ 6.551 & 15.54 & 1 \\ 6.829 & 14.93 & 1 \\ 6.094 & 13.9 & 1 \\ 4.82 & 15.75 & 1 \\ 5.456 & 13.92 & 1 \\ 6.179 & 16.56 & 0 \\ 5.129 & 16.8 & 1 \\ 6.444 & 17.2 & 1 \\ 6.289 & 17.94 & 0 \\ 6.443 & 17.2 & 0 \\ 6.999 & 14.5 & 0 \\ 6.594 & 15.21 & 0 \\ 6.567 & 17.52 & 0 \\ 6.491 & 16.1 & 1 \\ 5.133 & 15.38 & 3 \\ 5.309 & 14.1 & 1 \\ 6.704 & 16.5 & 0 \\ 6.063 & 15.2 & 1 \\ 6.114 & 15.8 & 1 \\ 6.043 & 16.75 & 0 \\ 6.536 & 15.82 & 0 \\ 5.939 & 16.4 & 2 \\ 6.266 & 14.6 & 3 \\ 5.678 & 17.3 & 1 \\ 5.016 & 17.8 & 0 \\ 6.472 & 15.99 & 0 \\ 6.166 & 14.5 & 1 \\ 6.601 & 15.3 & 1\end{array}$




$\begin{array}{rrr}6.757 & 15.9 & 0 \\ 6.007 & 17.4 & 0 \\ 5.639 & 17.1 & 0 \\ 6.007 & 12.6 & 1 \\ 6.171 & 16.4 & 0 \\ 6.114 & 17.8 & 0 \\ 6.47 & 14.6 & 0 \\ 6.472 & 13.8 & 1 \\ 6.706 & 17 & 0 \\ 6.587 & 14.2 & 1 \\ 5.632 & 17.1 & 0 \\ 6.549 & 15.2 & 1 \\ 6.211 & 16.1 & 0 \\ 6.512 & 14.7 & 3 \\ 6.66 & 14.7 & 1 \\ 6.281 & 15.6 & 0 \\ 6.172 & 17.2 & 0 \\ 5.584 & 17.4 & 0 \\ 4.969 & 17.8 & 1 \\ 6.73 & 14.8 & 0 \\ 5.903 & 14.8 & 1 \\ 6.874 & 15.9 & 0 \\ 6.006 & 16.4 & 1 \\ 5.883 & 16.8 & 1 \\ 6.335 & 16.7 & 0 \\ 5.761 & 17 & 0 \\ 5.9 & 16.7 & 1 \\ 5.67 & 17 & 0 \\ 6.243 & 14.6 & 1 \\ 5.133 & 17 & 1 \\ 6.042 & 17.8 & 0 \\ 6.599 & 15.1 & 1 \\ 6.747 & 16.9 & 0 \\ 5.657 & 17.9 & 0 \\ 6.509 & 17.1 & 0 \\ 6.168 & 16.4 & 0 \\ 6.164 & 15.3 & 0 \\ 4.818 & 17.8 & 0 \\ 6.784 & 17.4 & 0 \\ 6.688 & 16.2 & 0 \\ 5.345 & 17 & 1 \\ 5.918 & 17.5 & 0 \\ 6.683 & 17.2 & 0\end{array}$




$\begin{array}{rrr}5.941 & 16.9 & 0 \\ 5.893 & 16.1 & 1 \\ 5.34 & 16.3 & 1 \\ 5.409 & 15.2 & 2 \\ 5.341 & 15.8 & 1 \\ 5.58 & 15.8 & 1 \\ 6.491 & 16.3 & 0 \\ 4.846 & 17.6 & 1 \\ 6.204 & 17.2 & 1 \\ 6.764 & 16.6 & 1 \\ 5.904 & 15.5 & 1 \\ 5.958 & 17.1 & 3 \\ 6.824 & 17.7 & 0 \\ 6.126 & 17 & 0 \\ 6.812 & 15.4 & 0 \\ 6.772 & 15.8 & 1 \\ 6.59 & 16.8 & 1 \\ 6.754 & 15.9 & 0 \\ 6.233 & 17.6 & 0 \\ 5.943 & 17.6 & 0 \\ 6.622 & 16 & 0 \\ 4.758 & 17.4 & 0 \\ 5.527 & 17.8 & 1 \\ 6.576 & 16.8 & 1 \\ 6.404 & 17.3 & 1 \\ 5.924 & 16.7 & 0 \\ 5.956 & 14.6 & 0 \\ 5.963 & 16.3 & 1 \\ 4.848 & 17.2 & 0 \\ 4.96 & 16.6 & 2 \\ 6.611 & 17.9 & 0 \\ 6.143 & 17.1 & 0 \\ 6.219 & 17.1 & 0 \\ 6.45 & 17.3 & 1 \\ 6.24 & 17.2 & 1 \\ 6.334 & 16 & 0 \\ 6.826 & 15.8 & 1 \\ 6.651 & 16 & 0 \\ 4.062 & 16.8 & 1 \\ 6.454 & 16.9 & 3 \\ 5.804 & 16.5 & 0 \\ 6.629 & 15.8 & 0 \\ 5.758 & 17.7 & 0\end{array}$




$\begin{array}{rrr}6.798 & 17.6 & 0 \\ 5.484 & 16.5 & 0 \\ 5.851 & 17.6 & 3 \\ 5.965 & 17.7 & 0 \\ 4.361 & 17.8 & 0 \\ 6.987 & 16.4 & 0 \\ 6.586 & 17.5 & 0 \\ 5.655 & 17.9 & 0 \\ 6.211 & 15.8 & 0 \\ 6.669 & 15.2 & 3 \\ 6.144 & 17.1 & 0 \\ 6.68 & 14.6 & 1 \\ 4.613 & 17.2 & 0 \\ 6.137 & 17.1 & 0 \\ 6.241 & 14.9 & 0 \\ 6.373 & 16.5 & 2 \\ 5.731 & 16.9 & 0 \\ 6.624 & 16.6 & 1 \\ 4.384 & 17 & 0 \\ 6.949 & 15.5 & 0 \\ 5.106 & 16.4 & 0 \\ 5.523 & 16.8 & 0 \\ 5.784 & 17.8 & 0 \\ 5.343 & 16.5 & 0 \\ 6.518 & 16.4 & 0 \\ 5.655 & 16.2 & 0 \\ 5.154 & 17 & 0 \\ 5.357 & 15.8 & 0 \\ 5.585 & 15.3 & 0 \\ 5.976 & 16.4 & 0 \\ 6.859 & 16 & 1 \\ 5.708 & 17.4 & 1 \\ 6.411 & 16.4 & 0 \\ 6.42 & 16 & 0 \\ 6.443 & 17 & 0 \\ 5.704 & 17.6 & 0 \\ 6.165 & 15.6 & 1 \\ 6.324 & 15.2 & 0 \\ 6.867 & 17.7 & 0 \\ 4.933 & 17.6 & 0 \\ 6.291 & 16.4 & 0 \\ 5.871 & 16.3 & 0 \\ 6.483 & 17.8 & 0\end{array}$




$\begin{array}{rrr}6.074 & 16.2 & 1 \\ 5.478 & 16.7 & 1 \\ 6.305 & 17.5 & 0 \\ 6.743 & 16 & 0 \\ 5.599 & 17.9 & 0 \\ 5.771 & 17.7 & 0 \\ 5.258 & 17.7 & 0 \\ 5.146 & 16.8 & 0 \\ 6.488 & 16.3 & 0 \\ 6.356 & 17.7 & 1 \\ 6.963 & 16.6 & 0 \\ 5.337 & 16.6 & 1 \\ 4.704 & 16.9 & 0 \\ 6.635 & 17.6 & 0 \\ 6.177 & 17.2 & 0 \\ 6.426 & 15 & 1 \\ 6.208 & 17.9 & 0 \\ 6.223 & 16.7 & 1 \\ 6.124 & 15.8 & 0 \\ 5.56 & 16.9 & 0 \\ 5.933 & 16.6 & 0 \\ 4.787 & 16.7 & 0 \\ 5.951 & 17.3 & 0 \\ 6.89 & 16.6 & 0 \\ 6.085 & 17.8 & 0 \\ 5.403 & 16.2 & 0 \\ 6.856 & 16.2 & 0 \\ 5.381 & 17.1 & 0 \\ 6.863 & 16.8 & 0 \\ 6.49 & 17.9 & 0 \\ 5.895 & 16 & 0 \\ 5.442 & 16.3 & 0 \\ 6.241 & 16 & 0 \\ 6.093 & 16.6 & 0 \\ 6.414 & 17.4 & 0 \\ 6.695 & 17.3 & 0 \\ 6.964 & 16.4 & 0 \\ 6.01 & 16.6 & 2 \\ 5.736 & 16.7 & 0 \\ 5.568 & 17.6 & 0 \\ 5.259 & 17.2 & 0 \\ 6.778 & 17.2 & 0 \\ 5.747 & 16.9 & 0\end{array}$




$\begin{array}{rrr}6.033 & 17.9 & 0 \\ 6.41 & 17.3 & 0 \\ 6.219 & 17.5 & 0 \\ 5.634 & 17.9 & 0 \\ 6.834 & 16.4 & 0 \\ 6.975 & 16.3 & 0 \\ 6.395 & 16.9 & 0 \\ 6.231 & 16.2 & 0 \\ 6.186 & 16.1 & 0 \\ 6.782 & 17.2 & 0 \\ 6.546 & 16.5 & 0 \\ 5.714 & 17.6 & 0 \\ 6.764 & 17 & 0 \\ 6.373 & 17.9 & 0 \\ 6.383 & 15.4 & 0 \\ 6.916 & 16.3 & 0 \\ 4.816 & 17.1 & 0 \\ 5.479 & 16.6 & 0 \\ 6.347 & 17.8 & 0 \\ 5.913 & 17.4 & 0 \\ 6.682 & 15.1 & 0 \\ 5.772 & 17.1 & 0 \\ 4.93 & 17.5 & 0 \\ 6.806 & 15.7 & 0 \\ 6.625 & 17.3 & 0 \\ 6.852 & 17.6 & 1 \\ 6.44 & 16.7 & 0 \\ 5.559 & 17.9 & 2 \\ 5.313 & 17.5 & 1 \\ 6.128 & 16.3 & 0 \\ 6.479 & 17.7 & 0 \\ 6.01 & 17.2 & 0 \\ 5.104 & 17.6 & 0 \\ 6.187 & 17.2 & 0 \\ 5.775 & 17.4 & 0 \\ 6.45 & 16.8 & 0 \\ 6.253 & 17 & 0 \\ 4.255 & 17.8 & 0 \\ 6.556 & 17.2 & 0 \\ 6.662 & 16.6 & 0 \\ 5.995 & 17.5 & 0 \\ 6.687 & 17.4 & 0 \\ 6.175 & 17.6 & 0\end{array}$




$\begin{array}{rrr}6.376 & 17.9 & 0 \\ 6.657 & 17.4 & 0 \\ 6.883 & 15.6 & 0 \\ 5.933 & 17.5 & 0 \\ 6.704 & 16.5 & 0 \\ 6.229 & 17.1 & 0 \\ 5.568 & 17.3 & 1 \\ 4.89 & 17.7 & 0 \\ 6.556 & 16.8 & 0 \\ 5.409 & 16.9 & 0 \\ 6.178 & 17.6 & 1 \\ 6.066 & 16.1 & 0 \\ 6.76 & 16.7 & 0 \\ 6.564 & 17.7 & 0 \\ 5.955 & 17.6 & 0 \\ 6.794 & 16.4 & 0 \\ 6.872 & 15.4 & 1 \\ 5.976 & 17.7 & 0 \\ 6.819 & 17.5 & 0 \\ 5.982 & 16.3 & 0 \\ 5.866 & 17.1 & 1 \\ 6.757 & 16.7 & 0 \\ 6.837 & 17.3 & 0 \\ 6.444 & 17.7 & 1 \\ 6.93 & 17.9 & 0 \\ 6.983 & 16.5 & 0 \\ 5.61 & 17.1 & 0 \\ 6.718 & 17.2 & 0 \\ 6.154 & 17.7 & 0 \\ 6.914 & 17.5 & 0 \\ 6.383 & 17.9 & 0 \\ 5.104 & 17.4 & 0 \\ 6.014 & 17 & 0 \\ 5.793 & 17.5 & 0 \\ 6.792 & 17.9 & 0 \\ 6.681 & 17.3 & 0 \\ 6.679 & 15.5 & 0 \\ 6.778 & 17.4 & 0 \\ 6.108 & 17.9 & 0 \\ 5.635 & 16.8 & 0 \\ 6.543 & 17.7 & 0 \\ 4.909 & 17.4 & 0 \\ 6.131 & 17.8 & 0\end{array}$




$\begin{array}{rrr}5.985 & 16.9 & 0 \\ 6.922 & 17.1 & 0 \\ 6.024 & 17 & 0 \\ 6.742 & 17.7 & 1 \\ 6.582 & 17.5 & 0 \\ 6.337 & 16.2 & 0 \\ 6.578 & 17.1 & 0 \\ 5.74 & 17.7 & 0 \\ 5.617 & 17.9 & 0 \\ 6.547 & 17.9 & 0 \\ 6.653 & 17.4 & 0 \\ 6.334 & 17.3 & 0 \\ 6.565 & 17.8 & 0 \\ 6.588 & 17.6 & 0 \\ 6.829 & 17.5 & 0 \\ 6.809 & 16.7 & 0 \\ 6.636 & 17.9 & 0 \\ 6.977 & 17.6 & 0 \\ 6.583 & 17.8 & 0 \\ 6.209 & 17.5 & 0 \\ 6.52 & 17.1 & 0 \\ 6.832 & 16.9 & 1 \\ 6.011 & 16.9 & 0 \\ 6.576 & 17.2 & 2 \\ 4.863 & 17.6 & 0 \\ 5.903 & 17.9 & 0 \\ 6.981 & 17.6 & 0 \\ 5.441 & 17.7 & 0 \\ 6.929 & 16.3 & 0 \\ 6.017 & 17.3 & 0 \\ 6.969 & 16.4 & 0 \\ 5.168 & 17.9 & 0 \\ 6.407 & 17.4 & 0 \\ 6.048 & 17.8 & 0 \\ 4.309 & 17.6 & 0 \\ 6.064 & 17.1 & 0 \\ 5.93 & 17.3 & 0 \\ 6.958 & 17.9 & 3 \\ 6.671 & 16.6 & 0 \\ 6.724 & 17.3 & 0 \\ 6.775 & 17.7 & 0 \\ 6.731 & 15.4 & 0 \\ 6.693 & 17.1 & 0\end{array}$




$\begin{array}{rrr}6.069 & 17.8 & 0 \\ 6.332 & 17.7 & 0 \\ 5.325 & 17.7 & 0 \\ 6.619 & 16.5 & 0 \\ 5.796 & 17.8 & 0 \\ 5.618 & 16.7 & 0 \\ 6.953 & 17.3 & 0 \\ 6.572 & 17 & 0 \\ 6.79 & 17.3 & 0 \\ 6.435 & 16.8 & 0 \\ 6.879 & 17.2 & 0 \\ 6.605 & 17.5 & 0 \\ 6.582 & 17.7 & 0 \\ 3.947 & 17.5 & 1 \\ 6.39 & 17.9 & 0 \\ 5.719 & 17.2 & 0 \\ 5.246 & 17.8 & 0 \\ 6.821 & 16.9 & 1 \\ 5.772 & 17.9 & 0 \\ 5.564 & 17.5 & 0 \\ 5.719 & 17.9 & 0 \\ 6.776 & 17 & 0 \\ 6.774 & 17.8 & 0 \\ 6.35 & 17.4 & 0 \\ 6.966 & 17.5 & 0 \\ 6.765 & 17 & 0 \\ 6.452 & 17.9 & 0 \\ 6.924 & 17.7 & 0 \\ 6.55 & 17.8 & 0 \\ 6.797 & 17 & 0 \\ 6.662 & 17.2 & 0 \\ 6.763 & 17.6 & 0 \\ 6.891 & 17.7 & 0 \\ 6.441 & 17.9 & 0 \\ 6.253 & 17.4 & 0 \\ 6.547 & 16.8 & 0 \\ 6.373 & 17.9 & 0 \\ 6.709 & 17.9 & 1 \\ 4.476 & 17.8 & 1 \\ 6.197 & 17.6 & 0 \\ 6.957 & 17.9 & 0 \\ 6.349 & 17.7 & 0 \\ 6.585 & 17.3 & 0\end{array}$




$\begin{array}{rrl}5.921 & 17.9 & 0 \\ 6.981 & 17.4 & 0 \\ 6.814 & 17.6 & 0 \\ 6.486 & 17.6 & 0 \\ 6.128 & 17.3 & 0 \\ 6.7 & 17.9 & 0 \\ 6.874 & 16.7 & 0 \\ 6.816 & 17.6 & 0 \\ 6.852 & 17.7 & 0 \\ 6.773 & 16.3 & 0 \\ 6.245 & 17.9 & 0 \\ 6.556 & 17.1 & 0 \\ 6.572 & 17.5 & 0 \\ 6.711 & 17.2 & 0 \\ 6.981 & 17.7 & 0 \\ 6.616 & 17.8 & 0 \\ 6.567 & 17.8 & 0 \\ 6.865 & 17.7 & 0 \\ 6.485 & 17.8 & 0 \\ 6.957 & 17.3 & 0 \\ 6.903 & 17.9 & 0 \\ 6.796 & 17.2 & 0 \\ 6.395 & 16.9 & 0 \\ 6.7 & 17.4 & 0 \\ 4.893 & 17.8 & 0 \\ 6.486 & 17.2 & 0 \\ 6.952 & 17.2 & 0 \\ 6.332 & 17.8 & 0 \\ 6.789 & 17.9 & 0 \\ 6.099 & 17.2 & 0 \\ 6.742 & 17.7 & 0 \\ 6.153 & 17.7 & 0 \\ 6.515 & 17.8 & 0 \\ 6.278 & 17.8 & 0 \\ 6.514 & 17.4 & 0 \\ 6.635 & 17.8 & 0 \\ 6.443 & 17.4 & 0 \\ 6.771 & 17.5 & 0 \\ 5.798 & 17.6 & 0 \\ 6.264 & 17.9 & 0 \\ 5.683 & 17.5 & 0 \\ 6.707 & 17.6 & 0 \\ 6.376 & 17.8 & 0\end{array}$




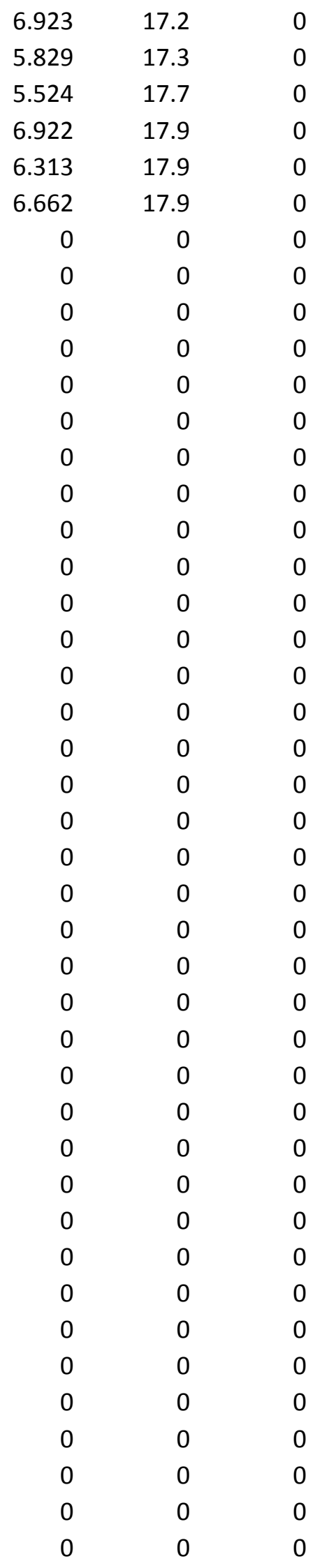




$\begin{array}{lll}0 & 0 & 0 \\ 0 & 0 & 0 \\ 0 & 0 & 0 \\ 0 & 0 & 0 \\ 0 & 0 & 0 \\ 0 & 0 & 0\end{array}$


ISSN 2331-1258 (online)

https://doi.org/10.3133/

ofr20171041 